\title{
Hematological Aspects on Dogs with Apparent Dysbiosis after Bacillus Subtilis, Bacillus Licheniformis and Pediococcus Acidilactici Probiotic Administration- Pilot Study
}

\author{
Maria-Cătălina MATEI*, Cristian Paul POPOVICI, Daniela NEAGU, Victoria BUZA, Andrei Radu SZAKACS, \\ Laura Cristina ȘTEFĂNUȚ
}

Faculty of Veterinary Medicine, University of Agricultural Science and Veterinary Medicine, 3-5 Calea Mănăștur Street, 400372 Cluj-Napoca, Romania

*corresponding author: catalina.matei@usamvcluj.ro

Bulletin UASVM Veterinary Medicine 77(2)/2020

Print ISSN 1843-5270; Electronic ISSN 1843-5378

doi:10.15835/buasvmcn-vm:2020.0018

\begin{abstract}
The aim of the study was to assess the effect of a probiotic product based on Bacillus subtilis, Bacillus licheniformis and Pediococcus acidilactici on hematological parameters for dogs with apparent intestinal dysbiosis. Also, a comparison between the results obtained before and after the treatment was made, in order to establish if the probiotic treatment is able to improve the hematological results for dogs with apparent dysbiosis. A total number of 5 dogs, aged between 7 months and 6 years old were clinically evaluated for gastro-intestinal problems that lead to the suspicion of apparent intestinal dysbiosis. The probiotic administration respected the producer recommendations and it was given to the dogs together with their usual food, one capsule/day, 30 days consecutively. On the first and 31 days of the study, blood samples were collected and hematological parameters were evaluated. A heterogeneity in the hematological results was observed. However, when results from day 0 were compared with results obtained in day 31, the variance was considered to be physiological. Also, the small diferences between the values before and after the treatment can not be attributed only to the probiotic treatment. The results obtained regarding the dynamics of the hematological parameters provided data that sustain the benefic effect of this probiotic combination, without a direct impact on hematological parameters.
\end{abstract}

Keywords: probiotic, dysbiosis, canine, Bacillus subtilis, Bacillus licheniformis, Pediococcus acidilactici

\section{Introduction}

Gastro-intestinal (GI) microbiome can be defined as a complex group formed from bacteria, arcanobacteria, fungi, protozoa and viruses that are able to colonize the mammals GI tract. GI microbiome is directly involved in some vital physiological processes (maintaining homeostasis, metabolic processes or immunological defense) (Barko et al., 2018).

If the GI microbiome structure is modified, the host may show signs of illness (Barko et al.,
2018). One of those pathologies is represented by dysbiosis. Dysbiosis is defined as a state represented by some modification on the normal composition of the microbiome that is associated with other pathologies that affect the host's microbial homeostasis. (Honneffer et al., 2014). Moreover, dysbiosis is characterized by a decrease of the number and bacteria diversity (Barko et al., 2018). Also, there are proofs that it is a link between dysbiosis and GI tract pathologies like inflammatory bowel syndrome, granulomatous 
colitis and irritable bowel syndrome (Honneffer et al., 2014).

All those pathologies can affect the host's normal lifestyle. Because it is a complex problem, there is not available yet a treatment that address all the symptoms. However, probiotics administered to dogs with dysbiosis can produce an improvement on the health state. Probiotics are capable to produce benefic effects to the host without changing the permanent structure of the microbiome. This phenomenon is possible by temporary colonization of the intestine (Ceapa et al., 2013; Barko et al., 2018).

Probiotics are used since $20^{\text {th }}$ century. Back then was reported a case of autoimmune arthritis that improved after probiotic treatment with some strains represented by Streptococcus lacticus and Bacillus bulgaricus (Warden, 1909; Barko et al., 2018). In veterinary medicine, several strains of probiotics are used. However, some of them are considered to be more resistant and to produce a higher effect. Generally, sporulated bacteria are considered to have a higher resistance. Bacteria's spores are a conservation form, being produced by bacteria as a defense mechanism and, moreover, as a conservation form when the environmental conditions are not suitable for surviving. By this mechanism, bacteria are able to assure their survival a long time in some conditions that, in a normal way, would destroy the vegetative form of the bacterium (Nicholson et al., 2000; Cutting, 2011).

The aim of the present study was to analyze the influence of a probiotic product with Bacillus subtilis, Bacillus licheniformis and Pediococcus acidilactici on hematological parameters on dogs with apparent dysbiosis. Also, a comparation between the results obtained before and after the treatment was made, in order to establish if the probiotic treatment is able to improve the hematological results for dogs with apparent dysbiosis.

\section{Materials and Methods}

The study was conducted at the University of Agricultural Sciences and Veterinary Medicine of Cluj-Napoca (on physiology and internal medicine departments) between May 2019 and June 2019. The study was approved by the Institutional Bioethics Committee by Decision no 130/20 December 2018.

\section{Study design}

A total of 5 adult dogs were enrolled in the study after a clinical examination, based on inclusion/exclusion criteria. Inclusion criteria were represented by GI manifestations representative for dysbiosis (diarrhea, vomiting and/or antibiotic treatment). Exclusion criteria were represented by the intestinal parasitism, chronic renal or hepatic failure. On day 0 of the study a full clinical examination was performed and blood was collected on EDTA in order to perform the hematological analysis. Between day 1 and 30 of the study the probiotic product containing B. subtilis HU58, B.licheniformis SL307, P. acidilactici, liver powder (FidoSpore ${ }^{\circledR}$ supplied by Microbiome Labs, LLC) was administered to the dogs, by the owner, respecting the manufacturer recommendations (daily, one capsule per day, during 30 days). On day 31 of the study the clinical examination as a follow-up was performed and the blood samples were collected again (one sample for each individual, on EDTA) in order to perform the hematological analysis.

\section{Study population}

All the 5 dogs were enrolled in the study after the clinical examination that revealed the meeting of the inclusion criteria. Also, all the dogs were enrolled in the study after their owners understood all the procedures and after that they signed a voluntary informed consent form. The study population was formed from P-01 (Labrador, 7 month, male with diarrhea and vomiting), P-02 (Akita Inu, 5 years and 9 months, female, with diarrhea and pancreatitis), P-03 (Golden retriever, 4 years, male, with dermatitis treated with antibiotics), P-04 (Boxer, 2 years, male, recurrent diarrhea induced by stress) and P-05 (Bucovina Shepperd, 4 years and 5 months, male, with recurrent diarrhea).

\section{Treatment}

The tested probiotic product was presented as capsules. The composition of the product was represented by the following bacterial strains: $B$. subtilis HU58, B.licheniformis SL307, P. acidilactici, plus an addition of liver powder (used in order to improve the taste of the product and to facilitate the ingestion). The capsules were administered during 30 days, one capsule per day, together with the usual food of the dogs.

\section{Investigations}

Clinical examination was performed using the great semiological methods. Therefore, the res- 
piratory rate, cardiac frequency and temperature were registered, together with all the observations made on the systems and the values obtained were compared with the reference intervals from Merk Veterinary Manual (Merck et al., 2016).

Hematological assessments were made using blood collected on anticoagulant (EDTA). ABACUS Junior VET was used in order to make the determinations, for the samples collected on day 0 and for the ones collected on day 31. Hematocrit (HCT), Hemoglobin (HBG), Total Red Blood Cells (RBC), Mean corpuscular volume (MCV), Mean corpuscular Hemoglobin (MCH), Mean Corpuscu- lar Hemoglobin Concentration (MCHC) and Total White Blood Cells (WBC) were assessed using the semi-automatic machine (Abacus Junior Vet User's Manual). Also, a differential white cell count was performed using a blood smear and counting cells using the microscope.

\section{Statistical analysis}

The data were analyzed using GraphPad Prism 8.0 software. Descriptive statistics was performed for all the data obtained. Also, $\mathrm{T}$ test was performed in order to compare the data from day 0 and those from day 31. Significance was set at $\mathrm{P}<0.05$.

Table 1. Statically analysis before and after the treatment

\begin{tabular}{|c|c|c|c|c|c|c|c|c|}
\hline \multirow[b]{2}{*}{ Parameter } & \multicolumn{6}{|c|}{ Descriprive statistics } & \multicolumn{2}{|c|}{ T test } \\
\hline & Min & Max & Mean & St Dev & St error of mean & CV (\%) & p value & Sign \\
\hline HCT pre-A & 38.93 & 43.28 & 41.67 & 1.7070 & 0.764 & 4.10 & \multirow{2}{*}{0.2273} & \multirow{2}{*}{ ns } \\
\hline HCT post-A & 36.04 & 42.31 & 39.26 & 3.0460 & 1.362 & 7.76 & & \\
\hline HGB pre-A & 18.20 & 20.50 & 19.38 & 0.9524 & 0.425 & 4.91 & \multirow{2}{*}{0.2400} & \multirow{2}{*}{ ns } \\
\hline HGB post-A & 16.00 & 19.80 & 18.02 & 1.6900 & 0.755 & 9.38 & & \\
\hline RBC pre-A & 5.75 & 8.04 & 6.65 & 0.8987 & 0.402 & 13.50 & \multirow{2}{*}{0.6023} & \multirow{2}{*}{ ns } \\
\hline RBC post-A & 5.48 & 7.46 & 6.42 & 0.7946 & 0.355 & 12.30 & & \\
\hline MCV pre-A & 54.00 & 69.00 & 63.4 & 6.1070 & 2.731 & 9.63 & \multirow{2}{*}{0.0418} & \multirow{2}{*}{$s^{*}$} \\
\hline MCV post-A & 53.00 & 66.00 & 61 & 4.9500 & 2.214 & 8.11 & & \\
\hline MCH pre-A & 22.50 & 33.70 & 29.46 & 3.2840 & 1.469 & 11.15 & \multirow{2}{*}{0.0400} & \multirow{2}{*}{$\mathrm{s}^{*}$} \\
\hline MCH post-A & 22.70 & 30.20 & 27.14 & 3.2840 & 1.468 & 12.09 & & \\
\hline MCHC pre-A & 44.70 & 48.90 & 46.6 & 1.7580 & 0.786 & 3.77 & \multirow{2}{*}{0.3760} & \multirow{2}{*}{ ns } \\
\hline MCHC post-A & 44.30 & 47.10 & 45.88 & 1.0920 & 0.488 & 2.38 & & \\
\hline WBC pre-A & 6.83 & 17.13 & 11.39 & 3.7500 & 1.670 & 32.97 & \multirow{2}{*}{0.8866} & \multirow{2}{*}{ ns } \\
\hline WBC post-A & 7.08 & 14.97 & 11.24 & 3.0750 & 1.375 & 27.35 & & \\
\hline $\mathrm{N}$ pre-A & 38.00 & 64.00 & 54.60 & 11.2600 & 5.036 & 20.62 & 0.0169 & $\mathrm{~s}^{*}$ \\
\hline $\mathrm{N}$ post-A & 62.00 & 75.00 & 68 & 5.2440 & 2.345 & 7.71 & & \\
\hline E pre-A & 4.00 & 10.00 & 6.2 & 2.3870 & 1.068 & 38.51 & \multirow{2}{*}{0.7765} & \multirow{2}{*}{ ns } \\
\hline E post-A & 1.00 & 11.00 & 5.4 & 4.3930 & 1.965 & 81.36 & & \\
\hline B pre-A & 0.00 & 0.00 & 0 & 0.0000 & 0.000 & 0.00 & \multirow{2}{*}{-} & \multirow{2}{*}{-} \\
\hline B post-A & 0.00 & 0.00 & 0 & 0.0000 & 0.000 & 0.00 & & \\
\hline M pre-A & 8.00 & 14.00 & 10.2 & 2.3870 & 1.068 & 23.41 & \multirow{3}{*}{$\begin{array}{l}0.8634 \\
0.0315\end{array}$} & \multirow{3}{*}{$\begin{array}{l}\text { ns } \\
\mathrm{s}^{*}\end{array}$} \\
\hline M post-A & 4.00 & 14.00 & 10.6 & 3.9750 & 1.778 & 37.50 & & \\
\hline L pre-A & 21.00 & 47.00 & 29 & 11.2000 & 5.010 & 38.63 & & \\
\hline L post-A & 10.00 & 22.00 & 15.8 & 5.4950 & 2.458 & 34.79 & & \\
\hline
\end{tabular}

pre-A- determination made on day 0; post-A- determination made on day 31; N- neutrophils; E- eosinophils; B- basophils; M- monocytes; Llymphocytes;

$\mathrm{s}^{*}$ - statistically significant $(\mathrm{P}<0.05)$; ns- without statistical significance $(\mathrm{P}>0.05)$ 


\section{Results and Discussion}

For all the dogs the clinical examination showed clinical signs of apparent dysbiosis. However, the 30 days follow-up showed a great improvement in the GI manifestation for all the dogs. The respiratory rate, hearth frequency and temperature were within normal limits on both examinations, for the whole population.

Hematological results showed a variance between the determinations (Table 1, Figure 1, Figure 2). From a statistical point of view, in case of neutrophiles and lymphocytes the standard deviation and standard error of mean registered slightly high values (N pre-A St Dev: 11.2600 and St error of mean: 5.036; L pre-A St Dev: 11.2000 and St error of mean: 5.010). These results could be assigned to the study group heterogeneity. For some parameters, the results obtained on day 31 showed an improvement. Moreover, when compared, MCV, MCH, neutrophils and lymphocytes, have a similar evolution before and after the treatment (Fig 3, Fig 4, Fig 5, Fig 6).

For all the 5 dogs enrolled in the study the preliminary clinical exam showed signs like diarrhea, vomiturition or skin problems, all being the reason to include the patients as subjects in the present study. Regarding the hematological parameters, heterogeneity was observed in all 5 cases. However, the differences recorded were more or less included in the physiological interval. Moreover, the heterogeneity of hematological results can be assigned to the heterogeneity of the study population.

Once the spores have been ingested, they need to resist the stomach barriers but in the other hand needs to be metabolically activated in the intestine. That's why it is of interest to understand the life cycle of Bacillus in the gut together with the action of $P$. acidilactici. In their review Bernardeau et al. (2017) are studying the main characteristics of beneficial Bacillus spores and vegetative cells (Bernardeau et al., 2017).

Bacillus spores once ingested are submitted to the gastrointestinal transit (enzymes, bile salts, peristaltic movements). They have a high tolerance for gastric acidity due to their structure. In the intestine, spores will germinate in presence of nutrients, lysozyme, salts, high pressures and cationic surfactants (dodecylamine). These agents will bind to the spore's receptors and will release a concentration of dipicolinic acid (DPA). This mechanism will trigger the entrance of water in the spore core. Subsequently rehydrated spores will start their germination. These processes lead to the presence of live Bacillus bacteria in the gut. Vegetative cells will proliferate and replicate. Finally, Bacillus will be present in stool and release in the environment (Bernardeau et al., 2017). The rate, the location and velocity of germination are important factors to take in consideration as potential probiotics (Bernardeau et al., 2017).

It is known that $B$. subtillis may not produce any changes in hematological parameters for animals. Hong et al. (2008) administered this bacterium strain to rabbits without any significant modification on the hematological results (Hong et al., 2008). Regarding the results obtained for dogs, Szakacs et al. (2019) showed that the combination between Bacillus strains and P. acidilactici does not produce important modifications at the level of hematological parameters when it is administered to healthy dogs (Szakacs et al., 2019).

A hematological assessment is a very common procedure used in clinics. Non-biased results are of a great importance in establishing a correct diagnostic. Because probiotics can have a systemic impact, by their complex mechanism of action, some parameters can be influenced by the treatment (Hong et al., 2008). Bacillus spores carry capacity to survive to intestinal transit. (Cutting, 2011). Studies have proved that Bacillus subtilis spores can germinate in the small intestine, grow, proliferate and finally re-sporulate. Bacillus spores in feces can reach $10^{\wedge} 4$ spores/gram (Cutting, 2011). Studies in mice models have shown an increase of immune system due to administration of germinating spores (Cutting, 2011). Moreover, works shown that vegetative cells play a greater role in immune response than spores. Bacillus can have different immune responses according to the strains and the host and other factors such as the stage of Bacillus (Bernardeau et al., 2017). By secreting antimicrobials like coagulant, amicoumacin and subtilisin Bacillus species is beneficial for the health. In fact, this property provides ability for the host to compete against pathogenic microorganisms (Cutting, 2011). Furthermore, Bacillus produces enzymes such as amylase, glucoamylase, protease, pectinase, and cellulase. Bacillus produces also vitamins such as riboflavin, cobalamin, inositol and carotenoids (Elshaghabee et al., 2017). As it can be seen, the 


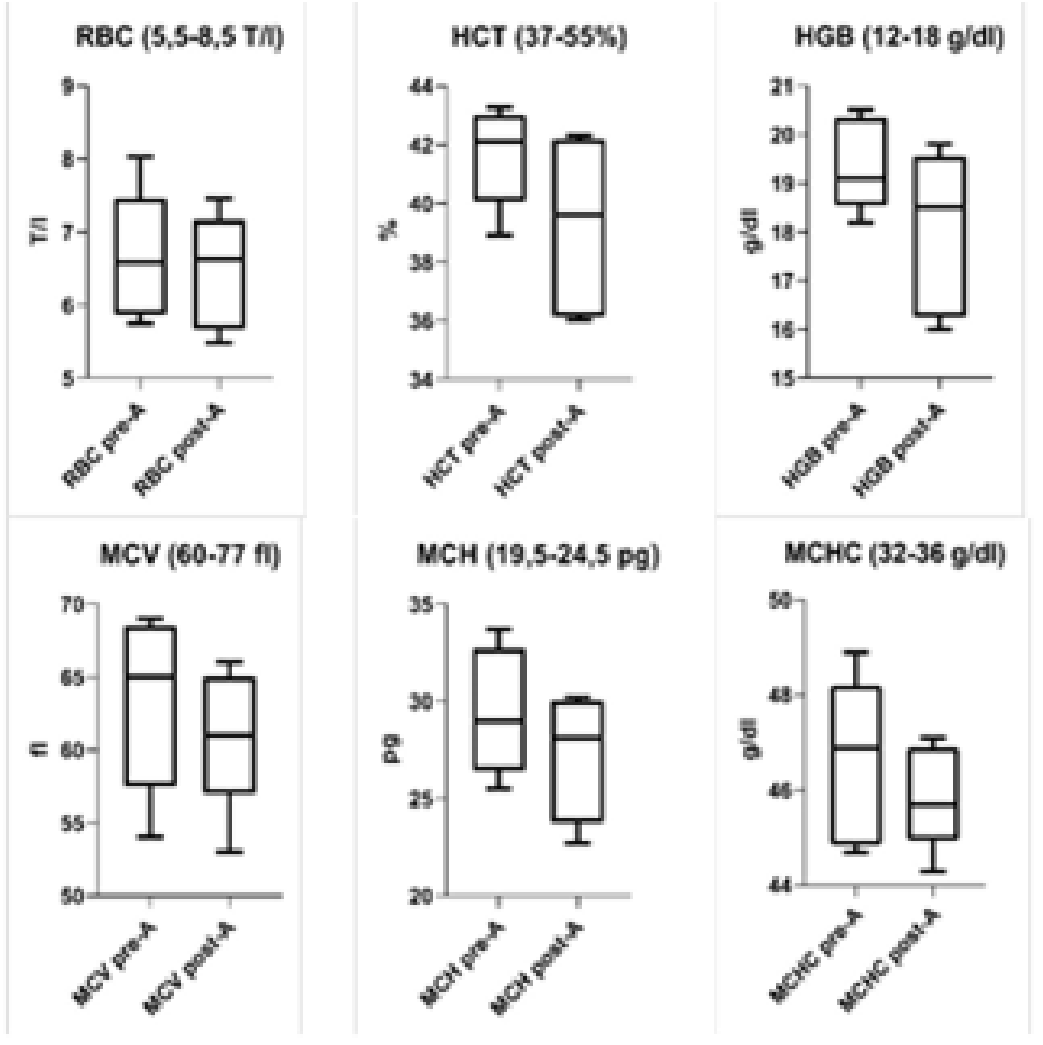

Figure 1. Red blood cells parameters- comparation before and after the treatment

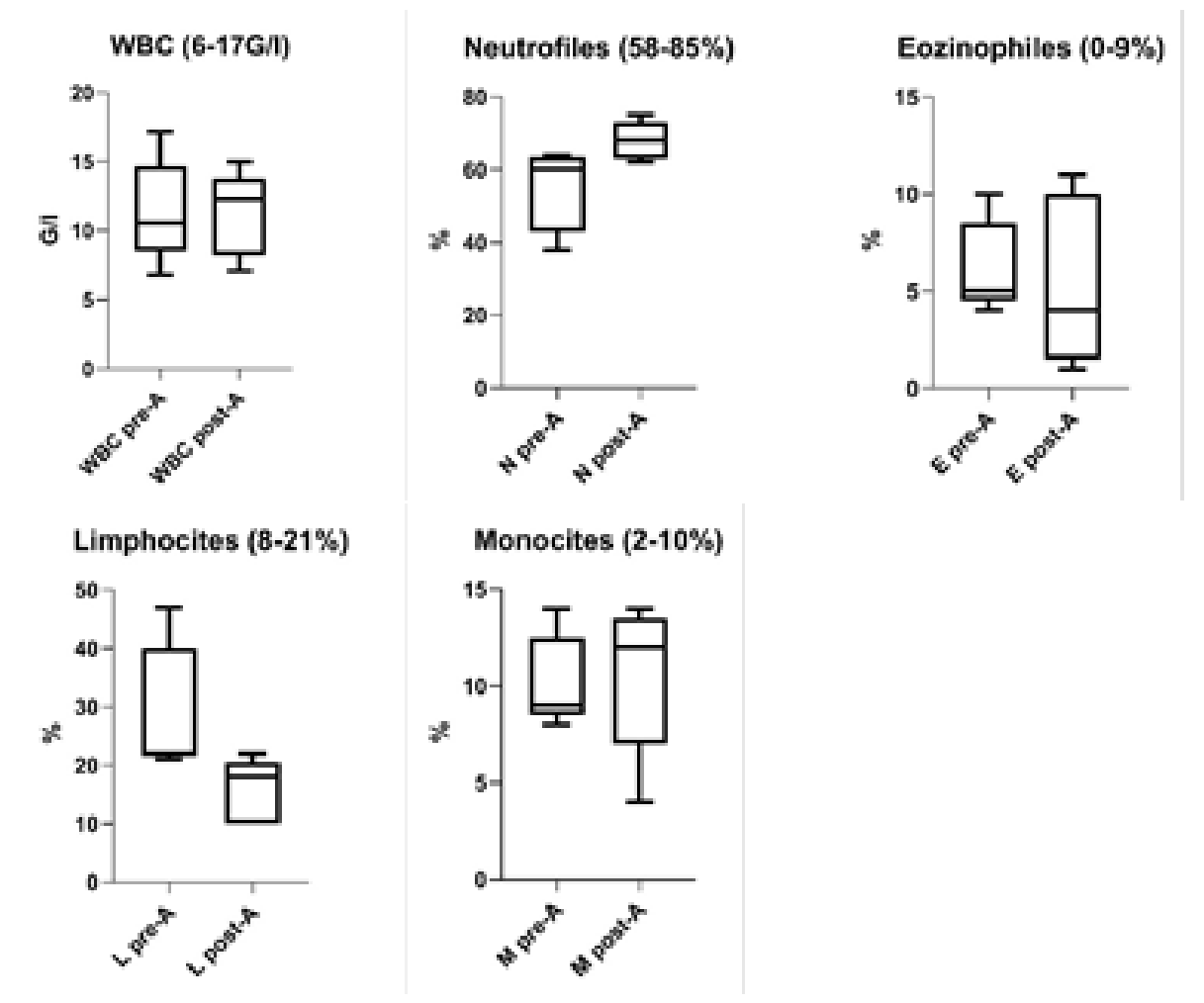

Figure 2. White blood cells parameters- comparation before and after the treatment 

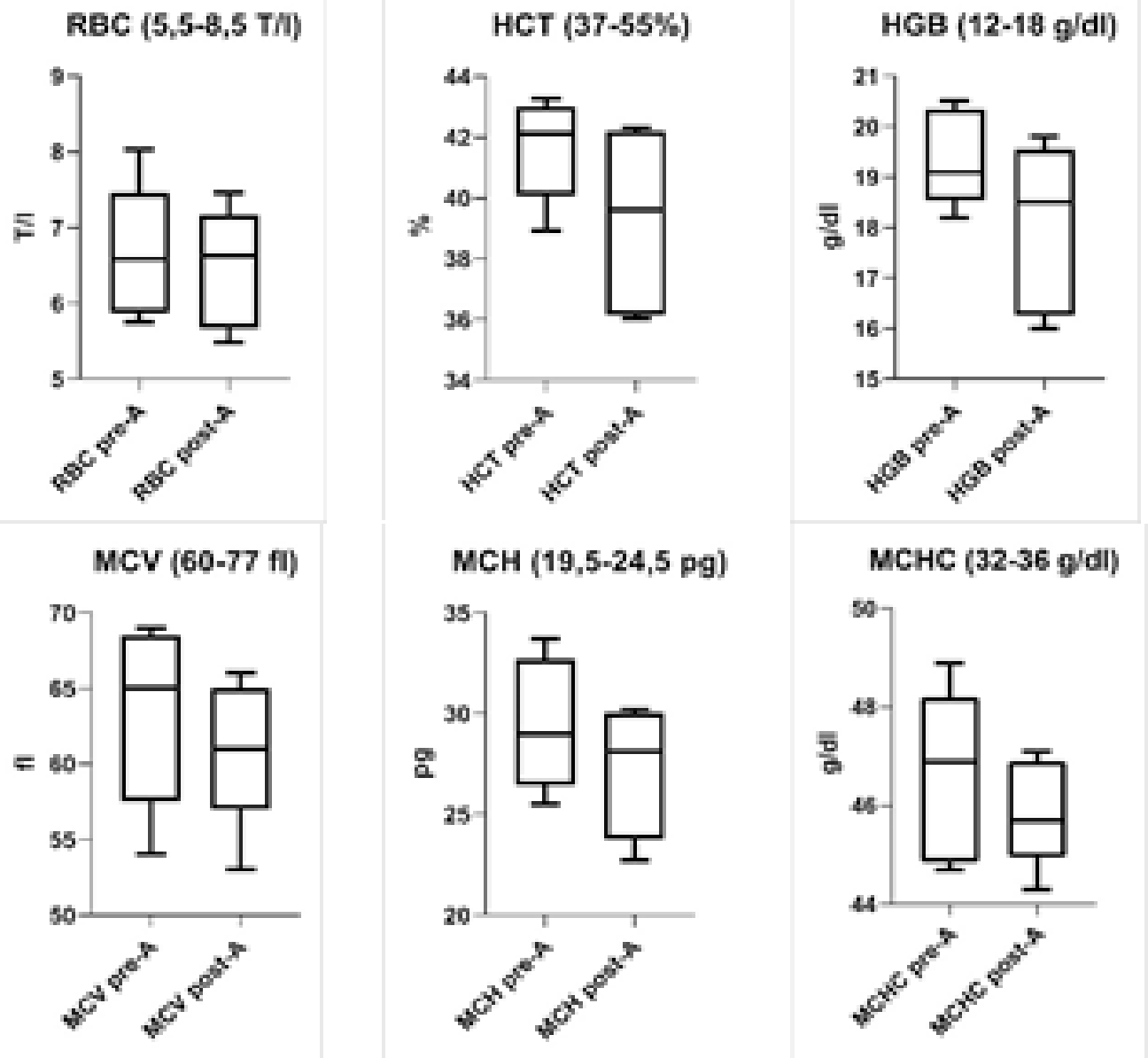

Figure 3. MCV Evolution before and after the treatment

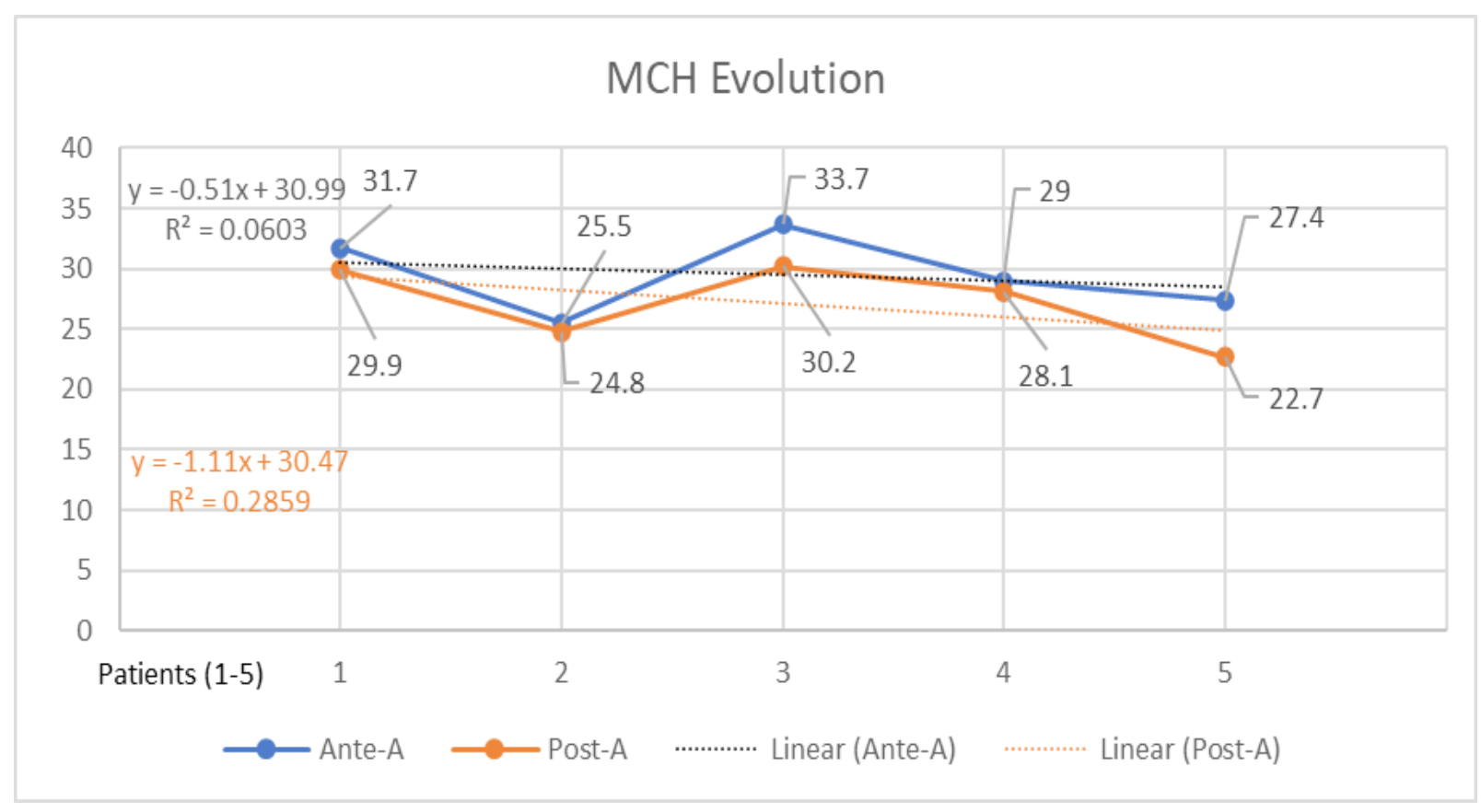

Figure 4. MCH Evolution before and after the treatment 
complex mechanism of action is working at a systemic level. Usually, hematological parameters are assessed in order to clarify some dilemmas regarding pathologies also with systemic influence. If a treatment is able to influence the hematological parameters, the interpretation of results can be biased and the diagnostic misunderstood. That can be considered a strong argument for establishing if a potential treatment is safe to use, without any influence on the assessed parameters.

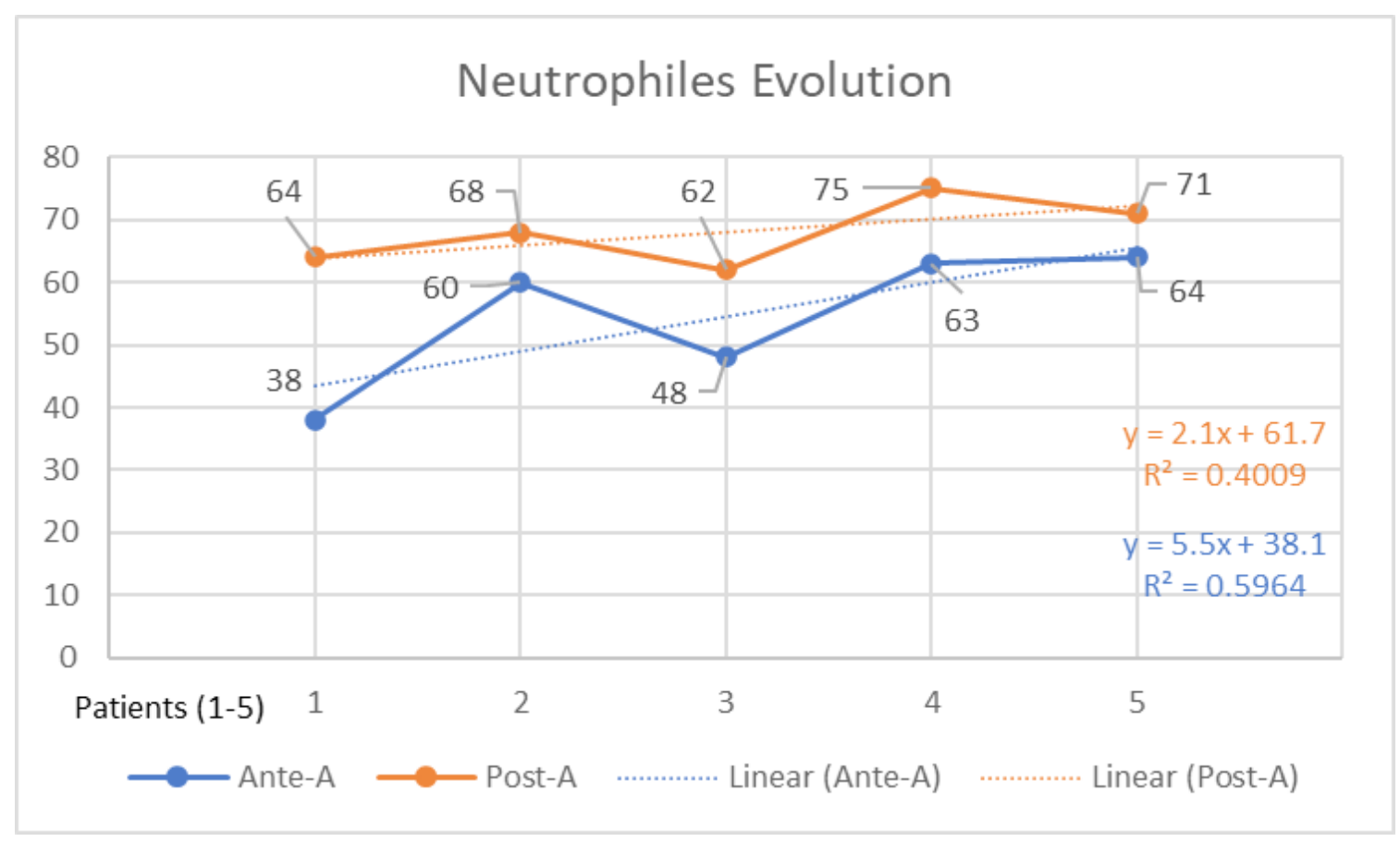

Figure 5. Neutrophils Evolution before and after the treatment

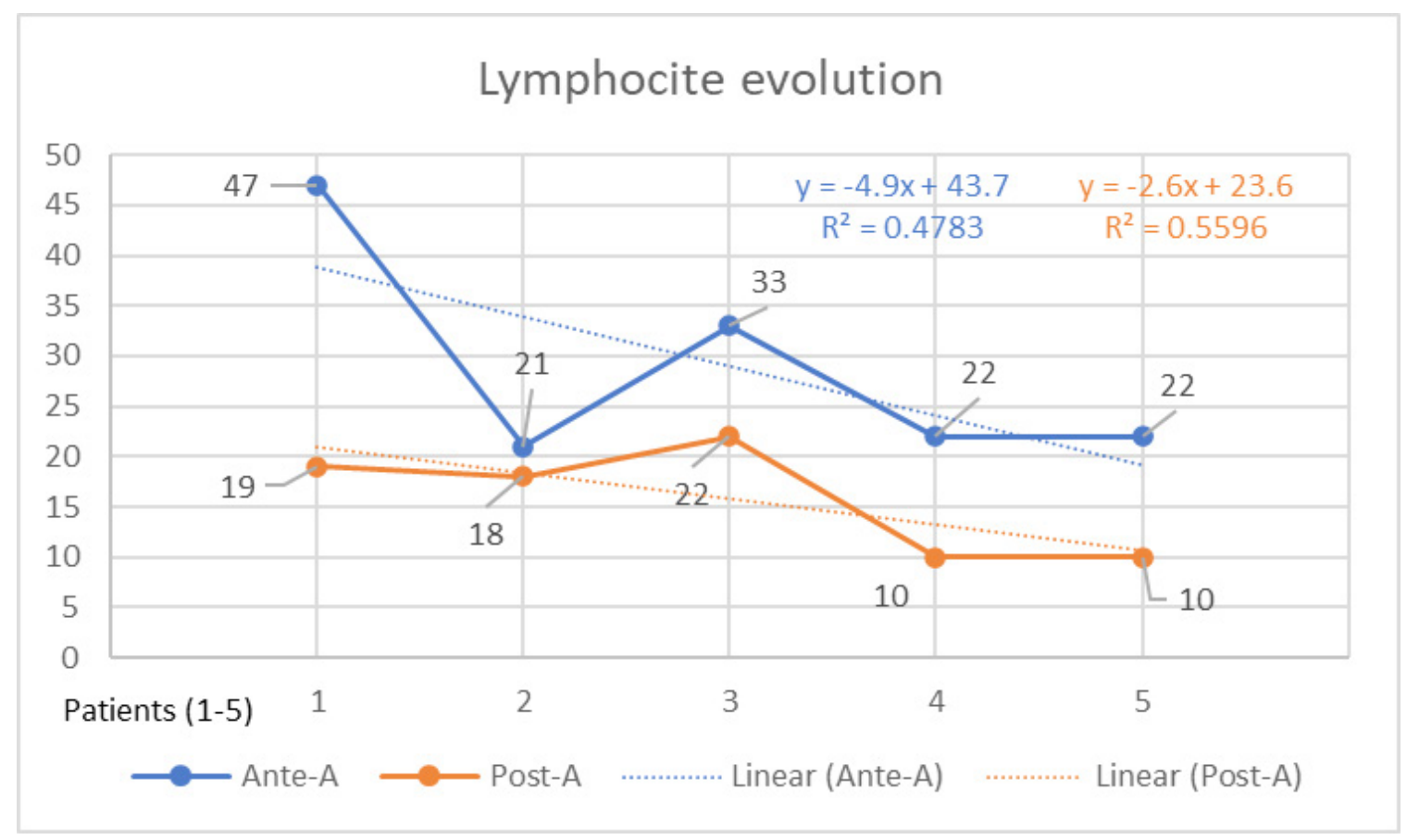

Figure 6. Lymphocyte Evolution before and after the treatment 


\section{Conclusion}

The results of the present study suggest that the combination between $B$. subtilis, B. licheniformis and $P$. acidilactici used as a probiotic combination does not strongly influence the hematological parameters in dogs with apparent dysbiosis.

Acknowledgments. This work was supported by MICROBIOME LABS PHYSICIANS EXCLUSIVE, LLC, Agreement no 30130/18 December 2018.

\section{References}

1. *** Abacus Junior Vet User's Manual

2. ***Merck \& CO, 2016. The Merck Veterinary Manual, 11th ed., Whitehouse station, New Jersey, USA.

3. Barko PC, Michael MA, Swanson KS, Williams DA (2018). The gastrointestinal microbiome: a review. Journal of Veterinary Internal Medicine, 32:9-25.

4. Bernardeau M, Lehtinen MJ, Forssten SD, Nurminen $P$ (2017). Importance of the gastrointestinal life cycle of Bacillus for probiotics functionality. Journal of Food Science and Technology, 54: 2570-2584.

5. Ceapa C, Wopereis H, Rezaiki L et al. (2013). Influence of fermented milk products, prebiotics and probiotics on microbiota composition and health, Best Pract Res Clin Gastroenterol, 27:139-155.
6. Cutting SM (2011). Bacillus probiotics, Food Microbiology, 28:214- 220.

7. Elshaghabee FMF, Rokana N, Gulhane RD, Sharma C, Panwar $H$ (2017). Bacillus as potential probiotics: status, concerns, and future perspectives. Frontiers in microbiology, 8, article 1490: 1-11.

8. Hong HA, Khaneja R, Tam NMK, Cazzato A, Tan S, Urdaci M, Brisson A, Gasbarrini A, Barnes I, Cutting SM (2009). Bacillus subtilis isolated from the human gastrointestinal tract. Research in Microbiology, 160: 134-143.

9. Honneffer JB, Minamoto Y, Suchodolski JS (2014). Microbiota alterations in acute and chronic gastrointestinal inflammation of cats and dogs. World Journal of Gastroenterology, 20:16489-16497.

10. Nicholson WJ, Munakata N, Horneck G, Melosh HJ, Setlow P (2000). Resistance of Bacillus endospores to extreme terrestrial and extraterrestrial environments. Microbiol. Mol. Biol. Rev, 64, 548e572: 1-1832.

11. Szakacs AR, Matei CM, Popovici C, Neagu D, Buza V, Macri A, Ștefănuț LC (2019). The influence of a probiotic product with Bacillus subtilis and Pediococcus acidilactici on some hematological and clinical parameters of healthy dogs. Lucrări Științifice - Medicină Veterinară, Universitatea de Științe Agricole și Medicină Veterinară „Ion Ionescu de la Brad" Iași, 62(2): 149-154.

12. Warden CC (1909). The toxemic factor in rheumatoid arthritis. Cal State J Med,7:299-301. 